\title{
33. DECONVOLVING WATER-GUN SEISMIC DATA
}

\author{
Neal W. Driscoll ${ }^{2,3}$ and Garry D. Karner ${ }^{2}$
}

\begin{abstract}
We present a filtering technique for deconvolving water-gun seismic reflection data using a composite signal recorded by sonobuoy receivers. The composite is composed of a primary and a sea-surface reflected signal and their respective ray paths can be calculated from the source-receiver geometry. The corresponding time delay $\Delta t$ is equal to the difference between the arrival times of the primary and the sea-surface reflected signals. By determining $\Delta t$ for a range of source-receiver offsets, a theoretical filter can be constructed and used to extract a series of statistically independent primary signals. After applying a moveout correction to the primary signals and averaging, the resultant can be used to generate synthetic composite signals at near-vertical incidence for different water-gun towing depths. We show that deconvolving the water-gun seismic reflection data with the calculated composite signal significantly improves the stratigraphic resolution of the seismic data. Further, the deconvolved seismic reflection data, our best estimate of the acoustic impedance contrasts as a function of depth, are in good agreement with independently derived acoustic impedance contrasts from downhole logging data at Sites 752 and 754.
\end{abstract}

\section{INTRODUCTION}

Broken Ridge, located in the southeast Indian Ocean, is an essentially continuous west-northwest- to east-southeast-trending oceanic plateau, more than $1000 \mathrm{~km}$ long. The portion shallower than $2000 \mathrm{~m}$ is approximately $100 \mathrm{~km}$ wide (Fig. 1). Broken Ridge and Kerguelen-Heard Plateau are conjugate rifted margins of a pre-existing, submarine plateau (Schlich, Wise, et al., 1989; Peirce, Weissel, et al., 1989). Rifting between Broken Ridge and Kerguelen-Heard Plateau commenced in the middle Eocene. Ocean Drilling Program (ODP) drilling at Broken Ridge addressed two major questions concerning lithospheric extension: (1) the role of sublithospheric mantle in initiating rifting (active vs. passive rifting) and (2) the vertical motions of rift flanks (i.e., Broken Ridge) during extension and the implications of such motions to the mechanical strength of extended lithosphere. The stratigraphy preserved on Broken Ridge records the vertical motion of the lithosphere during and after extension. Accurate correlation between the ODP drilling data and seismic reflection data (i.e., regional data) was crucial to the success of Leg 121 (Peirce, Weissel, et al., 1989).

ODP seismic surveys and subsequent site relocation aboard the JOIDES Resolution commonly use two 80 -in. ${ }^{3}$ water guns as a sound source. The water-gun signal is a composite of a primary signal and a sea-surface reflected signal, which limits the stratigraphic resolution of the water gun. Although use of the 80 -in. ${ }^{3}$ water gun has eliminated the problem of the bubble pulse, interference of the sea-surface reflected signal with the primary signal still occurs.

In this chapter, we present a filtering technique that removes the interference of the sea-surface reflected signal from the composite water-gun signal, allowing the primary signal to be obtained. Using synthetic composite signals for near-vertical incidence

\footnotetext{
${ }^{1}$ Weissel, J., Peirce, J., Taylor, E., Alt, J., et al., 1991. Proc. ODP, Sci. Results, 121: College Station, TX (Ocean Drilling Program).

${ }^{2}$ Lamont-Doherty Geological Observatory of Columbia University, Palisades, New York 10964, U.S.A.

${ }^{3}$ Also at Department of Geological Sciences, Columbia University, Palisades, NY 10964, U.S.A.
}

generated from the primary signal, we deconvolve the water-gun seismic reflection data. We show that deconvolving the seismic reflection data with the composite signal substantially improves the stratigraphic resolution of the data.

\section{METHODOLOGY}

\section{Source-Receiver Geometry}

The relative shape of a composite signal changes as the sourcereceiver offset increases because of the change in the path lengths between the primary and reflected sea-surface signal. The time difference between the arrival of the primary and sea-surface signal, $\Delta t$, is a maximum when there is a vertical alignment between the source and receiver (i.e., zero offset). In this case, $\Delta t$ is simply equal to twice the towing depth of the water gun divided by the velocity of sound propagation through seawater.

For non-zero source-receiver offsets, $\Delta t$ can be calculated from the source-receiver geometry shown in Figure 2. The sea-surface reflected signal for a given shot comprises two segments: (1) ray path $A B$ from the source to the sea-surface, and (2) ray path $B C$ from the sea-surface to the receiver (Fig. 2). It is necessary to know the sea-surface reflection point relative to the receiver (point $B$ ) for a given shot in order to calculate the length of the ray paths $A B$ and $B C$. Because the angle of incidence is equal to the angle of reflection, two similar triangles are created by the ray paths $A B$ and $B C$ and lines through the source and receiver normal to the sea-surface (Fig. 2). Therefore, the following equality exists for shot 1:

$$
\frac{D_{1}-x_{1}}{L}=\frac{x_{1}}{z_{o}}
$$

and solving for $x_{1}$ gives

$$
x_{1}=\frac{D_{1} \cdot z_{o}}{L+z_{o}} .
$$

The entire ray path $A B C$ for the sea-surface reflected signal can be determined once the sea-surface reflection point $B$ is known (Fig. 2):

$$
A B C=\left(x_{1}^{2}+z_{o}^{2}\right)^{1 / 2}+\left(\left[D_{1}-x_{1}\right]^{2}+L^{2}\right)^{1 / 2} .
$$




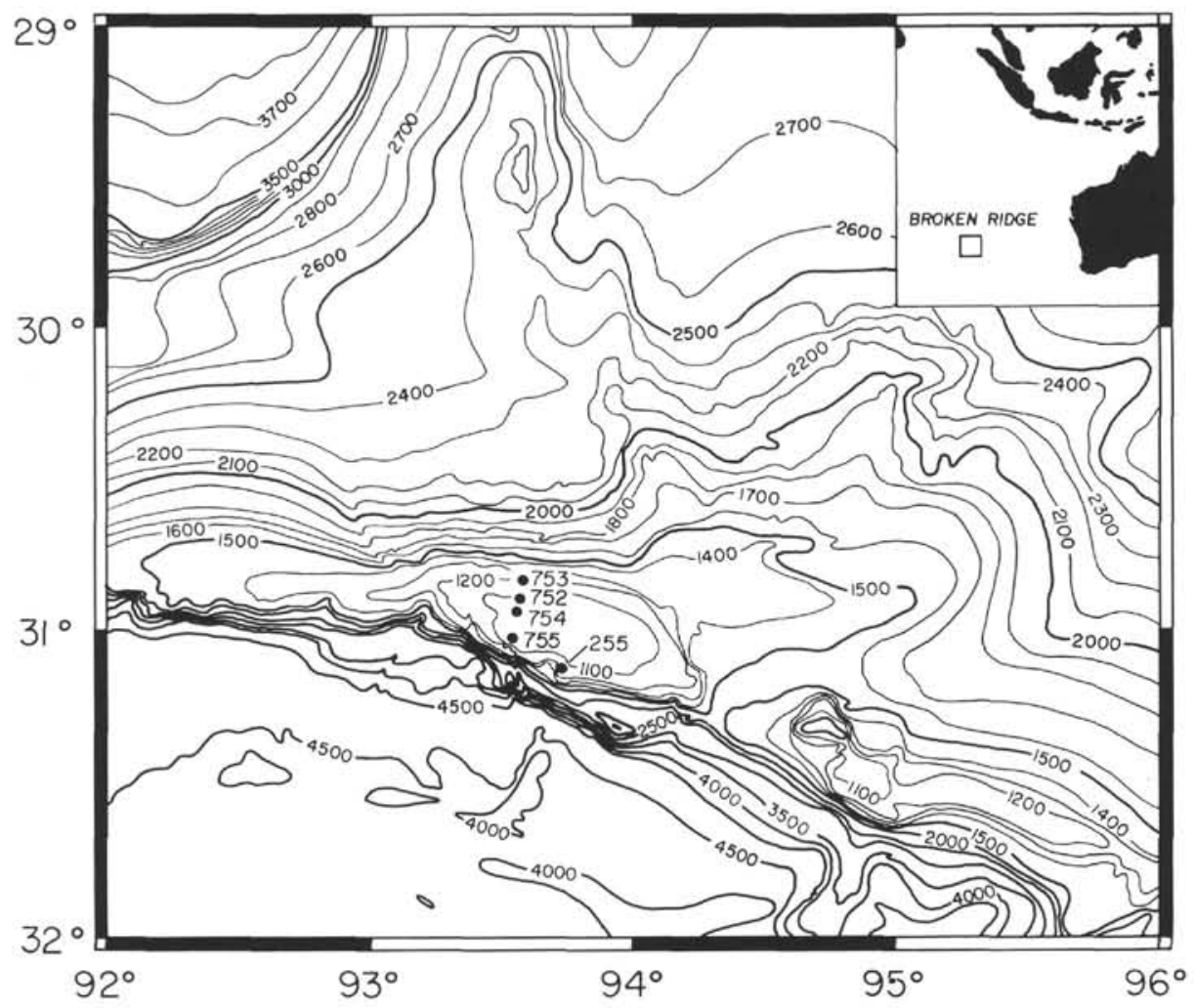

Figure 1. Bathymetry of Broken Ridge, in corrected meters, contoured from precision depth recordings. Deep Sea Drilling Project Site 255 and ODP Sites 752-755 are shown. Note that, for clarity, the contour interval changes from 100 to $500 \mathrm{~m}$ south of the escarpment.

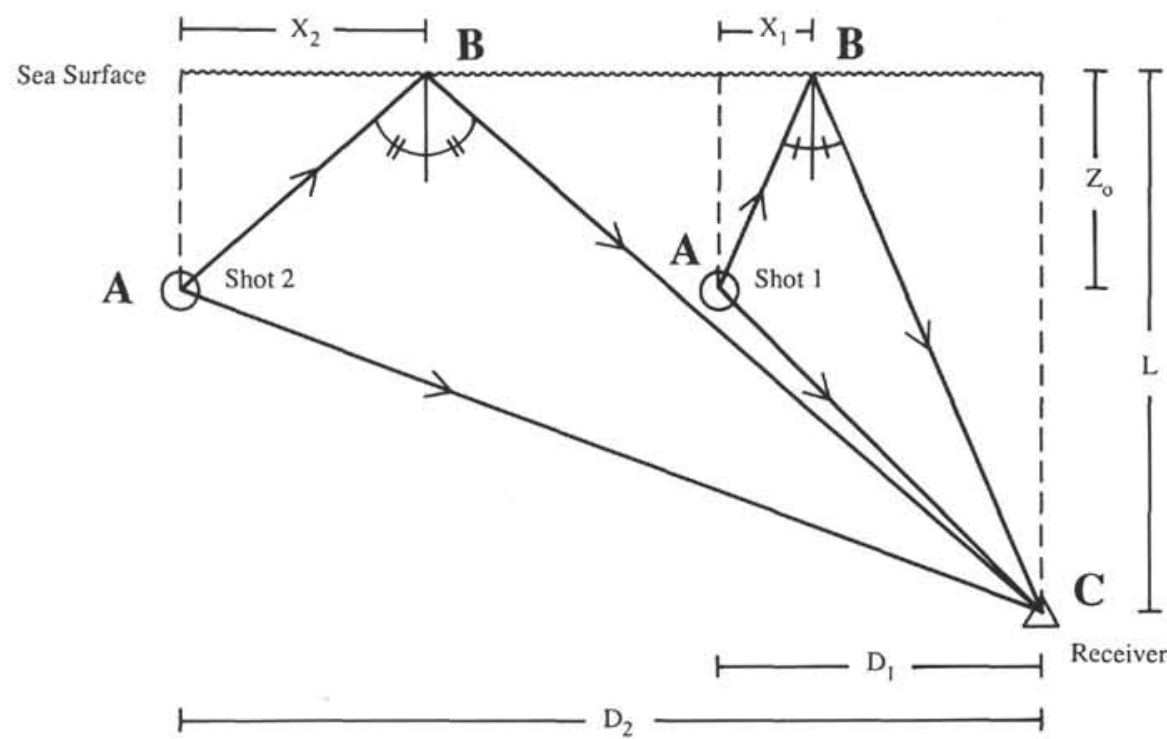

Figure 2. Source-receiver geometry for the water gun-sonobuoy receiver experiment. "A" denotes the shot position and " $\mathrm{B}$ " the sea-surface reflection position for a given shot. $D_{1}$ is the source-receiver offset for shot $1, z_{o}$ is the depth of the water-gun source, $L$ is the depth of the sonobuoy receiver, and $x_{1}$ is the horizontal distance from the shot to the sea-surface reflection point. $D_{2}$ and $x_{2}$ are the source-receiver offset and the reflection point for shot 2 , respectively. 
The ray path $A C$ for the primary signal is simply:

$$
A C=\left(D_{1}^{2}+\left[L-z_{o}\right]^{2}\right)^{1 / 2} .
$$

The above equations are applicable for any shot given the appropriate $D$ and $x$. For example, to calculate the ray path lengths of the primary and sea-surface reflected signal for shot 2 , substitute $D_{2}$ and $x_{2}$ for $D_{1}$ and $x_{1}$ in equations 3 and 4 , respectively (Fig. 2). The time difference between the two ray paths, $A B C$ and $A C$, equals $\Delta t$.

\section{Filter}

For calm sea-state conditions, the amplitude of the sea-surface reflected signal is almost equal to the primary signal. Consequently, the free surface-reflection coefficient $R$, given by the ratio of the reflected to primary signal amplitude, is approximately one (Jovanovich et al., 1983). The sea-surface reflected signal is phase-reversed and time-delayed by $\Delta t$ relative to the primary signal because it reflects off the air-water interface. The composite water-gun signal $f_{c_{1}}(t)$ therefore consists of: (1) the primary water-gun signal $f_{p_{1}}(t)$ and (2) the product of the free surface-reflection coefficient $(R)$ and the phase-reversed and time-delayed sea-surface signal $-f_{p_{1}}\left(t-\Delta t_{1}\right)$. In the time domain:

$$
f_{c_{1}}(t)=f_{p_{1}}(t)+R \cdot\left[-f_{p_{1}}\left(t-\Delta t_{1}\right)\right],
$$

where $t$ is time. Taking the Fourier transform of both sides of equation 5, we obtain:

$$
F_{c_{1}}(s)=F_{p_{I}}(s)-R \cdot F_{p_{1}}(s) e^{-i 2 \pi s \Delta t_{1}},
$$

where $s$ is frequency, and $F_{c_{1}}(s)$ is the composite water-gun signal for shot $1, F_{p_{1}}(s)$ is the primary signal, and $\Delta t_{1}$ is the time delay between the primary and the sea-surface reflected signals. Equation 6 can be simplified to the following:

$$
F_{c_{1}}(s)=\left(1-\operatorname{Re}^{-i 2 \pi s \Delta t_{1}}\right) \cdot F_{p_{1}}(s),
$$

in which we can see the linear filter operation of converting an input signal, $F_{p_{1}}(s)$, to an output signal $F_{c_{1}}(s)$. We can now obtain a primary signal by dividing each recorded composite signal by the appropriate filter for each $\Delta t$ (Fig. 3). In order to determine the best statistical representation of $F p(s)$, we obtain a number of independent estimates of the composite water-gun signal for increasing source-receiver offset:

$$
\begin{aligned}
& F_{c_{2}}(s)=\left(1-\mathrm{Re}^{-i 2 \pi s \Delta t_{2}}\right) \cdot F_{p_{2}}(s), \\
& F_{c_{3}}(s)=\left(1-\mathrm{Re}^{-i 2 \pi s \Delta t_{3}}\right) \cdot F_{p_{3}}(s), \\
& F_{c_{n}}(s)=\left(1-\mathrm{Re}^{-i 2 \pi s \Delta t_{n}}\right) \cdot F_{p_{n}}(s),
\end{aligned}
$$

where $F_{c_{n}}(s)$ is the composite signal for the $n^{\text {th }}$ sequential shot and $\Delta t_{n}$ is the delay between the primary and sea-surface reflected signals for that source-receiver offset. Applying a moveout correction and summing the primary signals obtained by the above equations significantly increases the signal-to-noise ratio. However, numerical instabilities develop when the filter approaches zero (i.e., nodal positions; Fig. 3). To avoid these instabilities, the filter amplitude was assigned a value of $10^{-4}$ within the nodes. This amplitude modification is equivalent to setting the free surface-reflection coefficient $(R)$ to just less than one and implies that the sea-surface is not a perfect reflector. Therefore, the theoretical filter $\left(1-\mathrm{Re}^{-i 2 \pi s \Delta t_{1}}\right.$; equation 7$)$ can never equal zero. Furthermore, instabilities can also arise from small source-receiver offsets $(=\leq 400 \mathrm{~m})$ because the amplitude of the theoretical filter approaches zero at both the low and high ends of the frequency spectrum (i.e., $0 \mathrm{~Hz}$, and the nyquist frequency, $500 \mathrm{~Hz}$; Fig. 3). To ensure that the amplitude of the theoretical filter remains stable, $\Delta t$ has to be less than $2 \mathrm{~ms}$ (given by twice the ratio of profile length/number of points).

\section{RESULTS \\ Primary Signal}

The composite signal was recorded by a hydrophone suspended from a military SSQ-57A sonobuoy from which analog signals were transmitted back to the Robert D. Conrad for digital recording at a sample rate of $1 \mathrm{~ms}$ (Fig. 4). The sonobuoy was deployed to attain a source signature for the water-gun system. At shotpoint 105 , the source is $6 \mathrm{~km}$ away from the sonobuoy receiver. The signal-to-noise ratio is approximately $3: 1$ (Fig. 4). The signal-to-noise ratio deteriorates when the ship approaches the sonobuoy receiver and so, for practical purposes, we restrict our study to large source-receiver offsets $(\approx \geq 3 \mathrm{~km})$. The amplitude spectrum for the composite signal (shotpoint 105) shows that the water gun has a broad-band source signature $(0-250 \mathrm{~Hz})$ with peak power at the low frequencies (Fig. 5).

The primary signal for shotpoint 105 is determined by dividing the composite signal by the theoretical filter for the appropriate $\Delta t$ (Fig. 6). The term "water-gun precursor" refers to a small positive pulse that is associated with the expulsion of water from the gun ports upon firing (Safar, 1984). The water-gun precursor is not clearly resolved by our filtering technique. The negative portion of the signal, prior to the large positive pulse, records the decay of the cavity subsequent to the water expulsion. The sharp positive peak corresponds to the final collapse of this cavity (Fig. 6). The primary signal determined by this technique is in good agreement with primary water-gun signals recorded by hydrophones (Safar, 1984; French and Henson, 1978). A more comprehensive explanation of the water-gun firing cycle is presented by Safar (1984) and French and Henson (1976). The amplitude spectrum for shotpoint 105 indicates that the primary signal is broad band $(0-250 \mathrm{~Hz})$ with signal strength decreasing toward high frequencies (Fig. 7).

Figure 8 demonstrates that the primary signals determined by this technique are very similar from one shot to another. A moveout correction, determined by cross-correlating adjacent signals, has been applied to these primary signals to align the signals in time (Fig. 9). The moveout appears linear (Fig. 9). Furthermore, the moveout calculated by cross-correlation vs. that estimated by navigation, shipboard logs, and the direct-wave ( $D$-wave) arrival are in good agreement; there is less than a 3-ms discrepancy between the techniques. Stacking and numerically averaging the primary signals serve to significantly decrease the spurious noise while enhancing the primary signal $f_{p}(t)$ (Figs. 6 and 10).

\section{Composite Signal}

Having resolved the primary signal, synthetic composite signals for vertical incidence can be generated for different watergun towing depths by phase-reversing and time-delaying the primary signal in order to simulate its reflection from the sea-surface. The simulated sea-surface reflected signal is then added to the primary signal. In the time domain, the synthetic composite signal shows little sensitivity to changes in $\Delta t$ (Fig. 11). However, in the frequency domain, the spectrum is dominated by interference notches due to the destructive interference between the primary and sea-surface reflected signals (Dragoset, 1990). The first non-zero frequency notch is indicative of the towing depth of the water gun (Dragoset, 1990). The interference notches shift to lower frequencies with increasing gun depth because of the dependence of $\Delta t$ on the source depth $\mathrm{z}_{o}$ (Fig. 12). At near-vertical incidence, the following equation relates gun depth to the first 


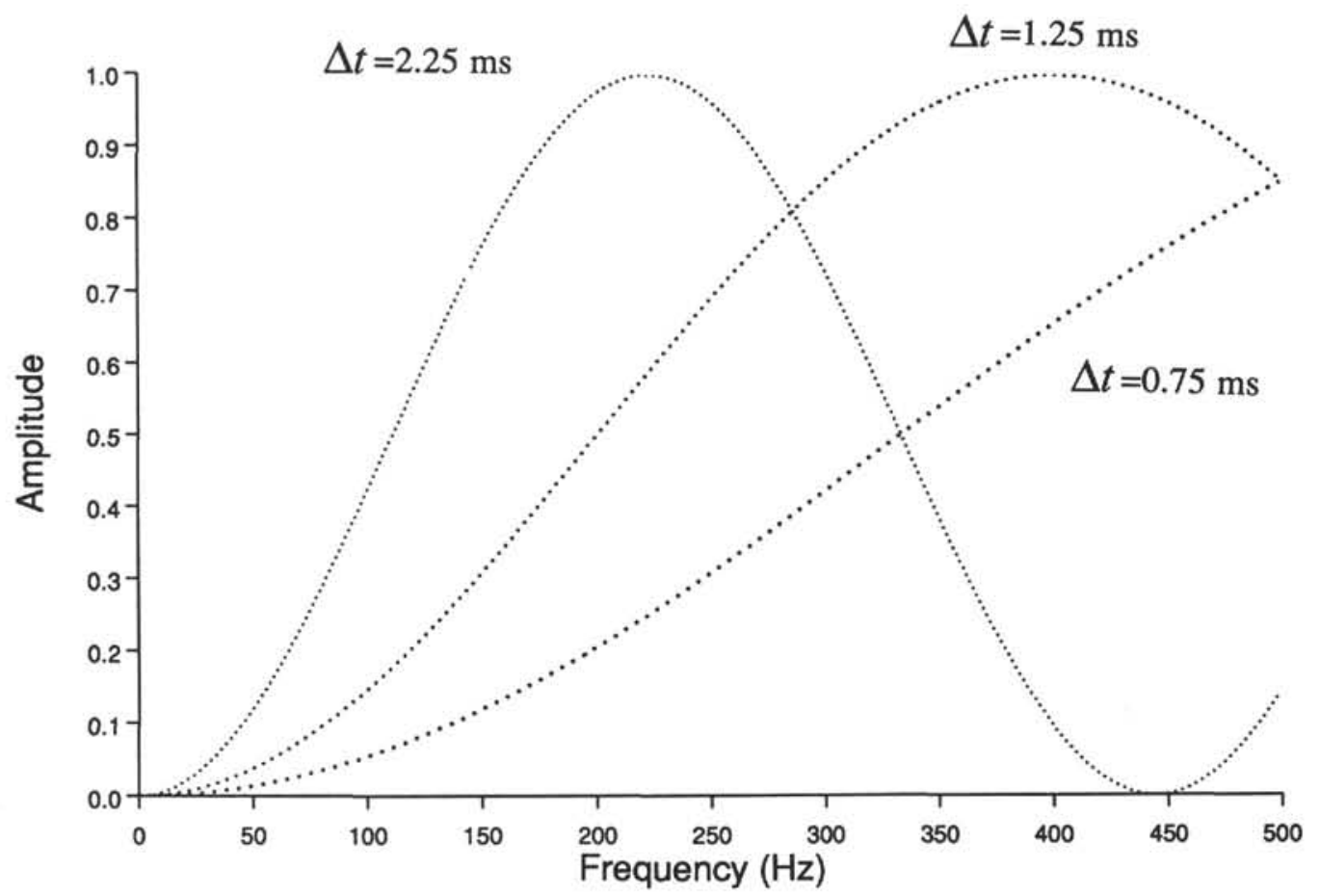

Figure 3. The filter $\left(1-\mathrm{e}^{-i} 2 \pi s \Delta t\right)$ to remove the sea-surface reflected signal from the recorded composite signal for a different $\Delta t$. Note the change in the filter with decreasing $\Delta$ t.

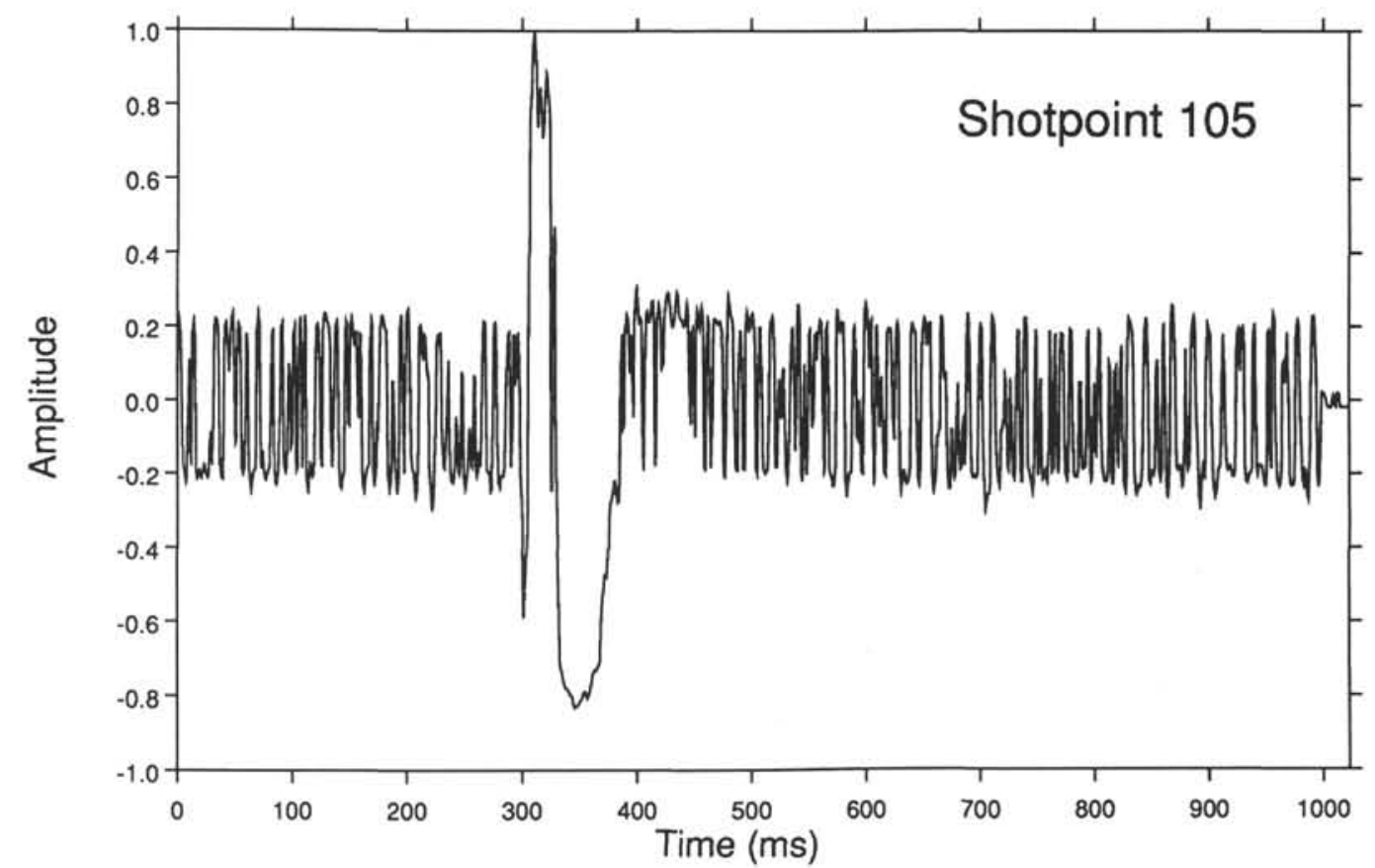

Figure 4. A water-gun composite signal (shotpoint 105) recorded by a SSQ-57A sonobuoy receiver. The sensor consisted of a hydrophone suspended at a depth of $122 \mathrm{~m}$ below the sonobuoy from which analog signals were telemetered back to the ship. The signal was digitally recorded at a 1 -ms sample rate. 


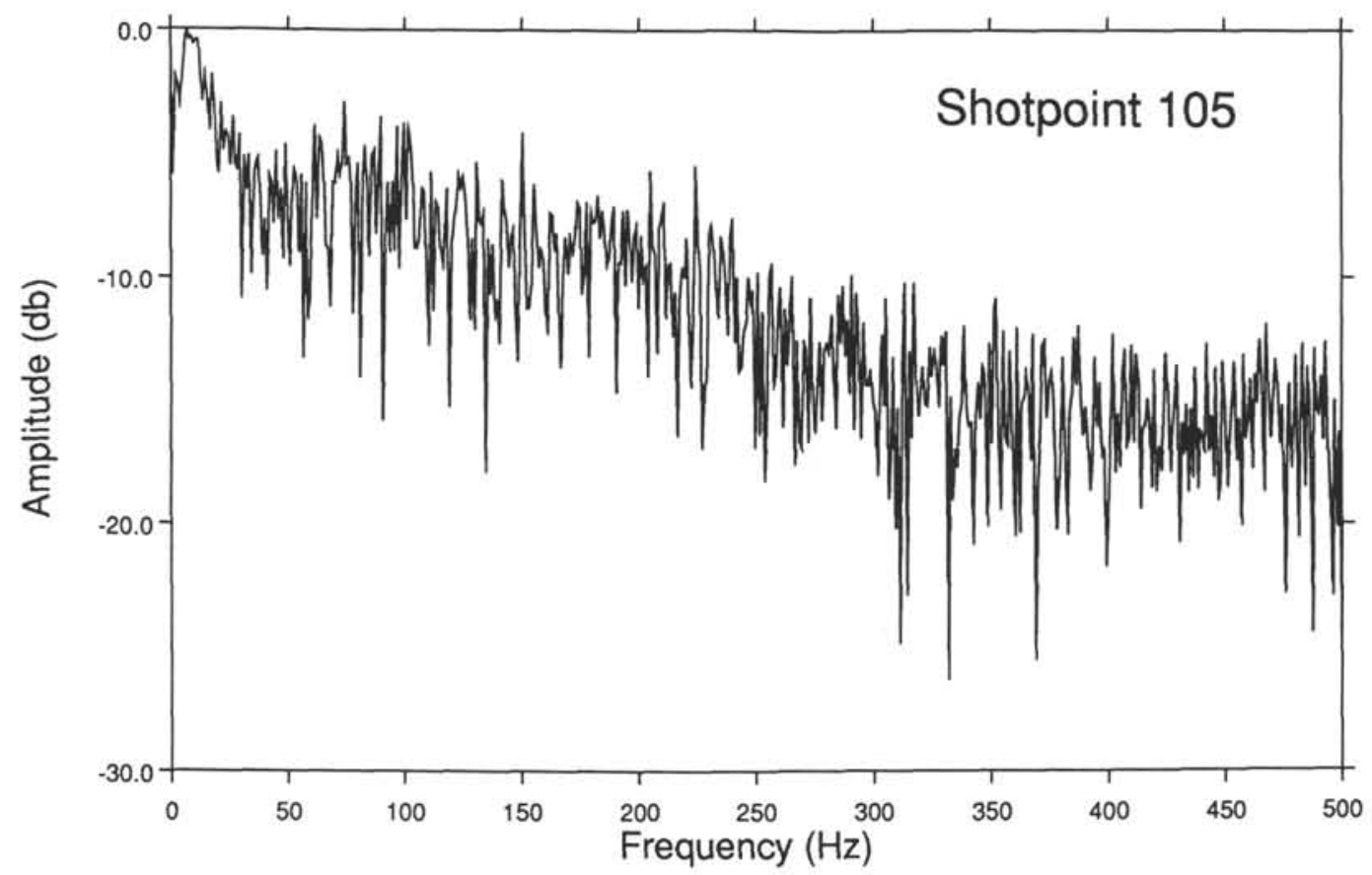

Figure 5. Amplitude spectrum for shotpoint 105 showing broad-band signature of the water gun. Note that the peak amplitude is concentrated in the low frequencies.

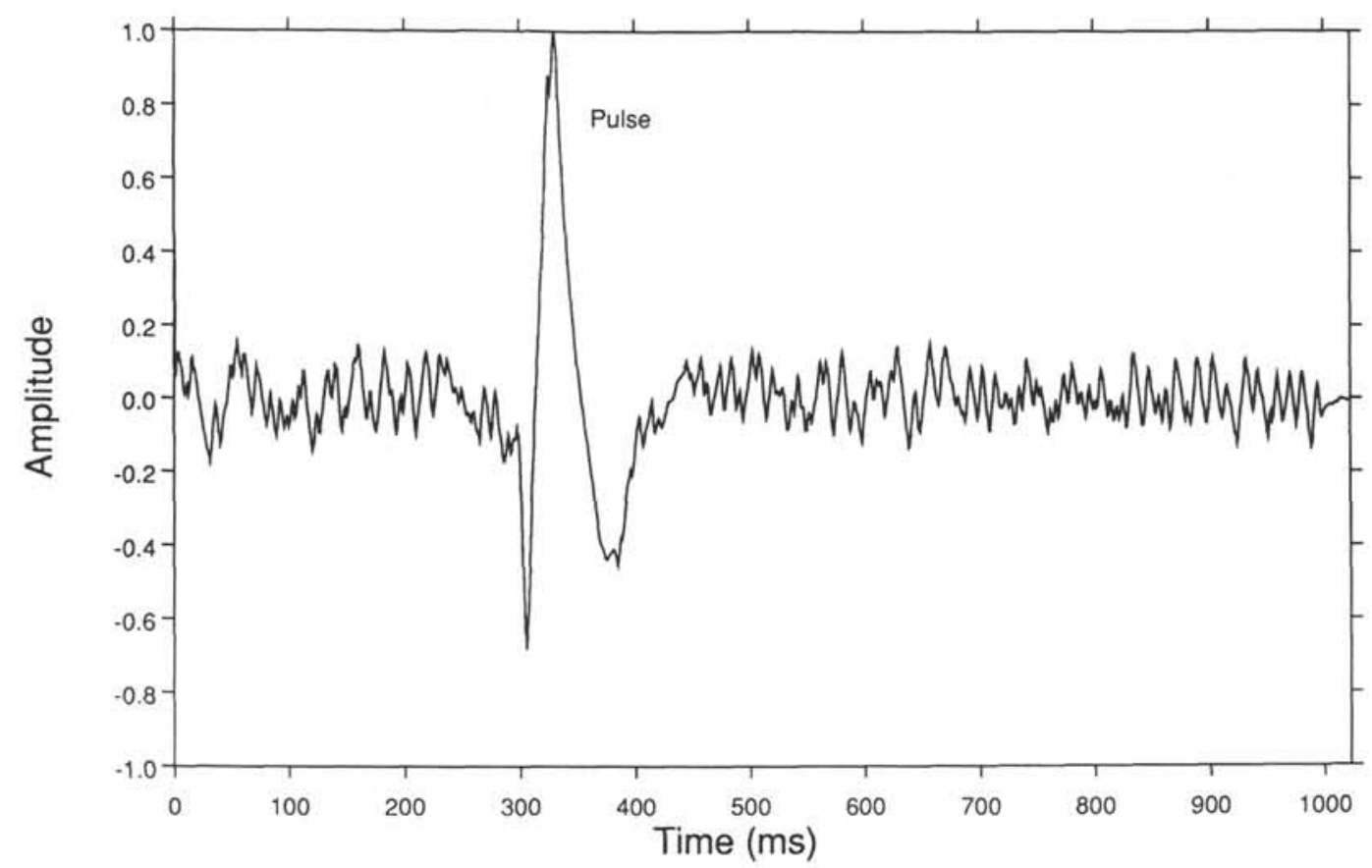

Figure 6 . The determined primary signal for shotpoint 105 . The composite signal was divided by the filter to remove the sea-surface reflected signal. The pulse observed in the primary signal is caused by the final collapse of the cavity. Prior to the collapse, the cavity decays and results in the observed negative amplitudes. An expulsion of water from the gun ports creates

non-zero frequency at which the interference notch occurs (Dragoset, 1990):

$$
f=\frac{V_{w}}{2 \cdot z_{o}} .
$$

For example, when $\Delta t=6 \mathrm{~ms}$ (gun depth $=4.5 \mathrm{~m}$ ), the notch occurs at $166 \mathrm{~Hz}$ (Fig. 12).

Deconvolution of a given seismic line requires knowledge of the water-gun towing depth. If the water depth during the seismic survey is significantly greater than the distance between the seismic source and the first active section of the streamer (i.e., 


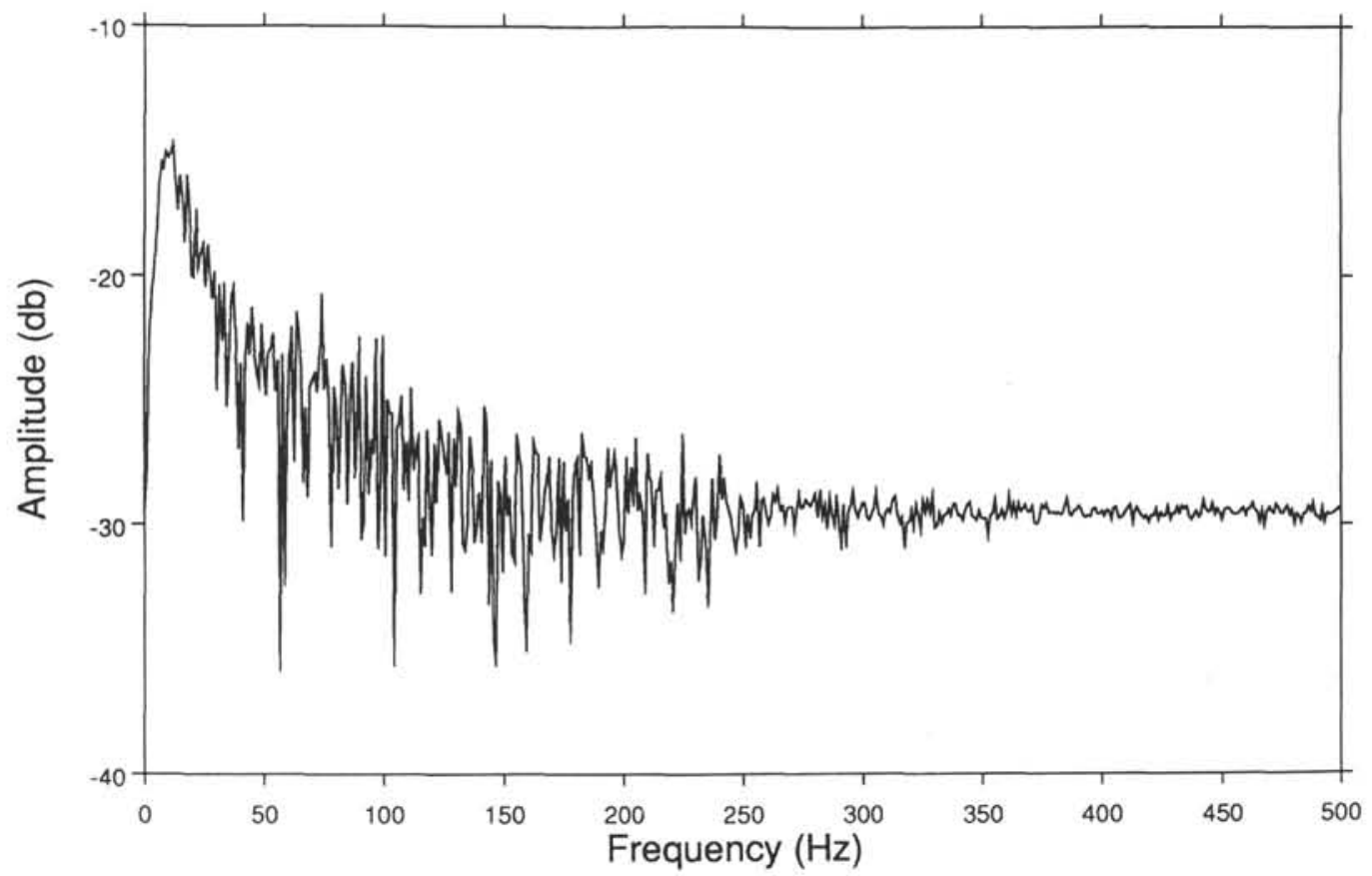

Figure 7. Amplitude spectrum for the primary signal (shotpoint 105) showing broad-band signature of the water-gun primary. Note that the peak amplitude is concentrated in the low frequencies.

hydrophone group), then the active section is recording near-vertical reflections. The appropriate $\Delta t$ to use when deconvolving a specific seismic reflection line can be determined by summing several shots recorded by the streamer and calculating the amplitude spectrum (Fig. 13). In this case, the interference notch for the summed composite signals recorded by the streamer (Conrad cruise 2708 , or RC2708, line 20) appears to be centered around $130 \mathrm{~Hz}$. The frequency at which the notch occurs corresponds to a gun depth of just under $6 \mathrm{~m}(\Delta t=8 \mathrm{~ms})$. Therefore, a composite signal with a $\Delta t=8 \mathrm{~ms}$ should be used during the deconvolution.

\section{Deconvolution}

Water-gun seismic reflection data were collected for the predrilling geophysical survey of Broken Ridge during RC2708. Seismic reflection line 20 is a dip line across Broken Ridge on which all the ODP sites (752-755) are located (Peirce, Weissel, et al., 1989; Figs. 1 and 14). The seismic reflection data were filtered, migrated, and deconvolved in order to optimize the stratigraphic resolution of the data (Fig. 15A-D).

In Figure 15A, a 20 - to $140-\mathrm{Hz}$ band-pass filter was applied to the seismic reflection data. The edges of the filter were tapered with a cosine function to avoid leakage. The first seafloor event results from the water-gun precursor (i.e., the expulsion of water from the gun ports). This event is low amplitude and is parallel to the underlying reflector.

Figure 15B illustrates seismic data that were deconvolved with the composite signal $(\Delta t=8 \mathrm{~ms})$ prior to the application of a 20 to $140-\mathrm{Hz}$ band-pass filter. Deconvolution has been used on seismic reflection data for the last 25 years and a detailed description of seismic deconvolution is given by Jurkevics and Wiggins (1984), Newman (1986), and Robinson and Treitel (1980). After deconvolution, the amplitude spectrum of the seismic reflection data is almost flat, allowing the broad-band capability of the water gun to be better exploited. In Figure 15C, a $20-$ to $140-\mathrm{Hz}$ bandpass filter was applied to the seismic reflection data after migration. Velocity information needed for the migration and the spherical divergence correction was determined by interpreting reflection and refraction data recorded by SSQ-57A sonobuoys (Driscoll et al., 1989). The first arrival due to the precursor is still observed in the seismic reflection data, but deeper reflectors are imaged more clearly after the migration and spherical divergence correction. Figure 15D illustrates the results when line 20 is migrated and corrected for spherical divergence, deconvolved with the composite signal, and then band-pass filtered with a 20 to $140-\mathrm{Hz}$ filter. Note that the first arrival due to the-water gun precursor is removed (Fig. 15D), and more impedance contrasts are imaged as a result of using more of the frequency content of the water gun, as in Figure 15B.

\section{Correlation of Seismic Stratigraphy to Lithostratigraphy}

From Figure 15A-D it is clear that deconvolution improves the seismic reflection data by: (1) removing the water-gun precursor and (2) qualitatively increasing the stratigraphic resolution of the data. However, a more rigorous test of the deconvolution technique involves correlating the processed profiles with the ODP drilling data (Peirce, Weissel, et al., 1989). Site 754 is on the central part of Broken Ridge, approximately $10 \mathrm{~km}$ north of the prominent southern scarp (Fig. 16). Site 754 was positioned to sample the oldest lithology onlapping the unconformity in order to further constrain the time interval over which the rifting and uplift occurred (Peirce, Weissel, et al., 1989). Two hiatuses were identified from ODP drilling, a middle Eocene hiatus and an Oligocene hiatus. At both Sites 752 and 754, the hiatuses are separated by a limestone cherty gravel with iron-stained quartz sand grains. Due to the unconsolidated nature of the gravel, core recovery was poor (Site 754 Cores $121-754 \mathrm{~A}-15 \mathrm{X}$ to $-17 \mathrm{X}$; Site 752 Core $121-752 \mathrm{~A}-12 \mathrm{X})$. The thickness of this gravel unit is approximately $30 \mathrm{~m}$ at Site 754 and thins toward both the north and south. At Site 752 the gravel unit is only $10 \mathrm{~m}$ thick and no gravel unit is observed at Sites 753 and 755 (Peirce, Weissel, et al., 1989).

The Oligocene and mid-Eocene hiatuses identified from drilling on Broken Ridge are resolved in the seismic reflection data prior to deconvolution (Peirce, Weissel, et al., 1989). However, 


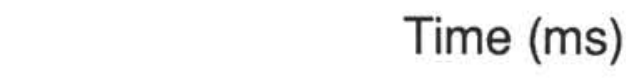

음
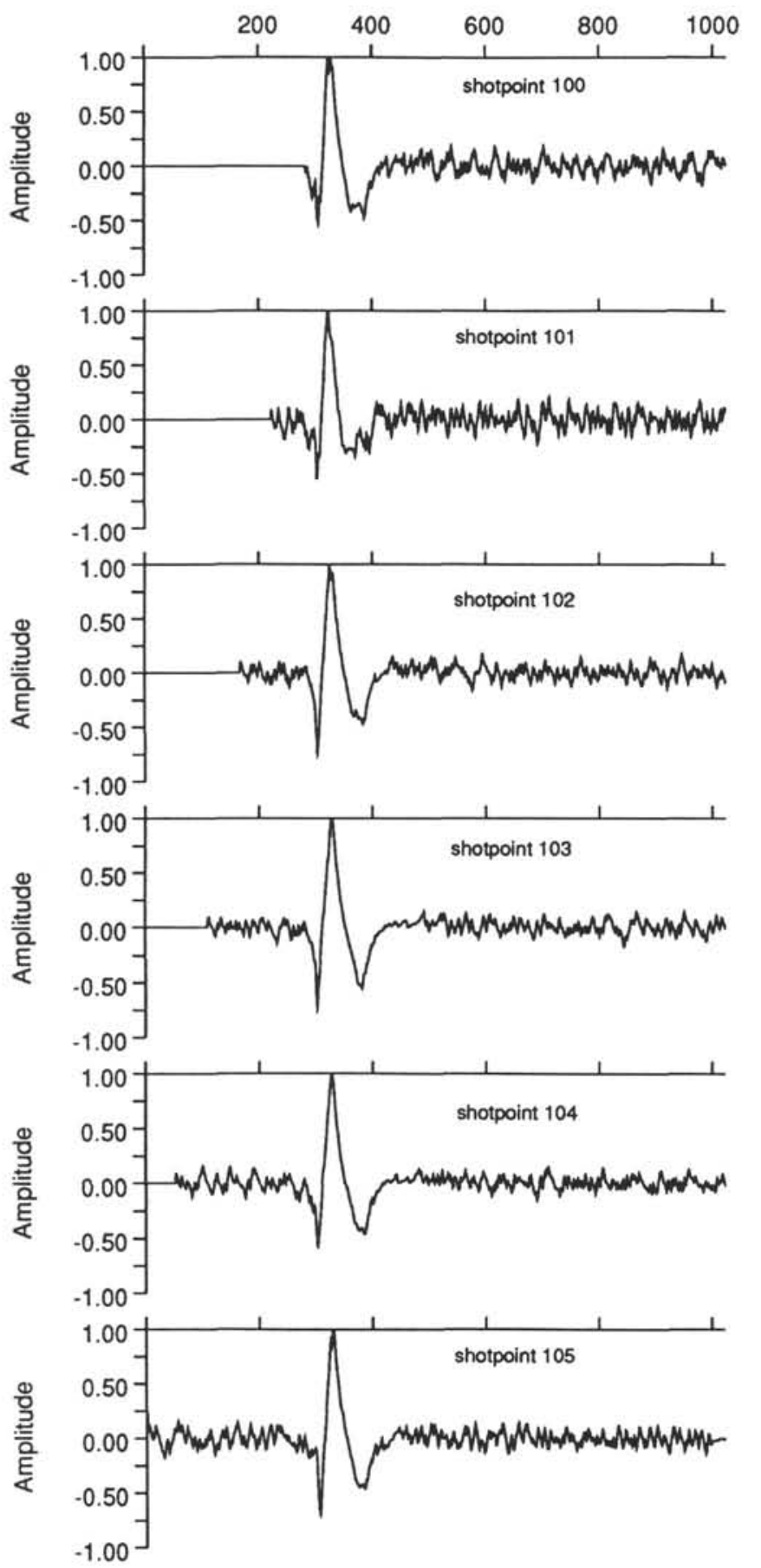

Figure 8. Determined primary signals for shotpoints 100-105. A moveout correction has been applied. Note the stability of the primary signals.

the position where the hiatuses coalesce across Broken Ridge is not resolved (Fig. 15A). Deconvolving the seismic reflection data allows better resolution of the gravel unit and the two bounding unconformities (Figs. 15B and 16). The mid-Eocene hiatus correlates with the prominent angular unconformity across Broken Ridge. The roughness of this unconformity is much better imaged

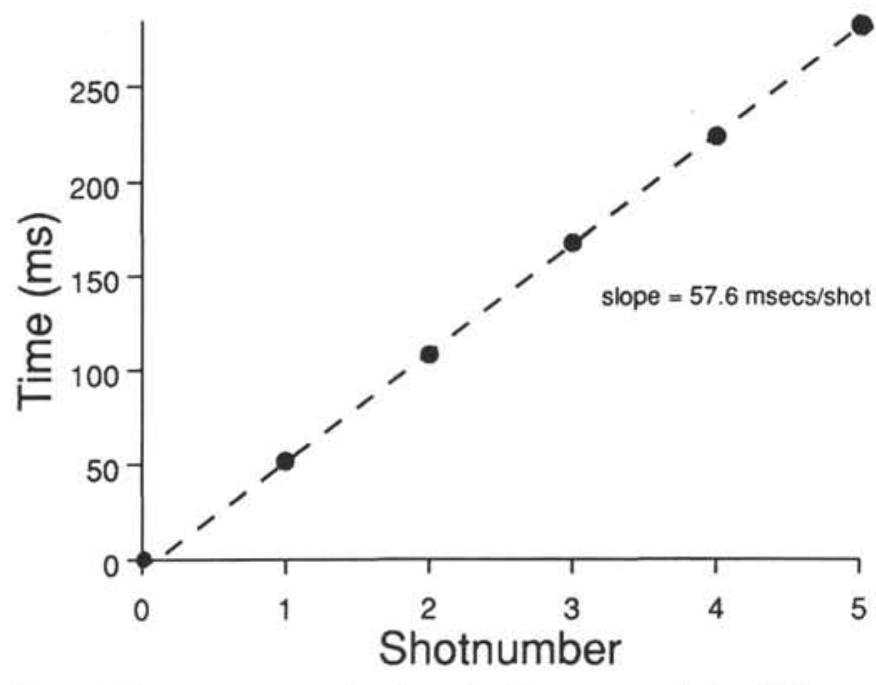

Figure 9. The moveout correction determined by cross-correlation of adjacent primary signals. The moveout correction determined by this method is 57.6 $\mathrm{ms} / \mathrm{shot}$. It compares well with the moveout correction determined by navigation, shipboard logs, and the $D$-wave arrival, which is $55 \mathrm{~ms} / \mathrm{shot}$.

in the deconvolved seismic data (Fig. 16). In addition, we are able to resolve the thinning of the overlying gravel by onlap onto the underlying mid-Eocene unconformity. The seismically imaged thickness and onlap position of the gravel unit across Broken Ridge correlates well with the drilling data (Peirce, Weissel, et al., 1989; Fig. 16).

Deconvolving the seismic reflection data with the composite signal should provide the best estimate of the acoustic impedance contrasts downsection (i.e., the "earth filter"). Estimates of the acoustic impedance contrasts were also independently determined from downhole logging data recorded at Sites 752 and 754. If our deconvolution technique has been successful, then there should be good agreement between the acoustic impedance contrasts determined from the downhole logging data and the deconvolved seismic reflection data. Downhole acoustic impedance contrasts (i.e., reflectivity series) were calculated using velocity and density data recorded at a $0.153-\mathrm{m}$ sampling interval (Peirce, Weissel, et al., 1989). Given the average seismic velocity of $2.0 \mathrm{~km} / \mathrm{s}$, the water gun can resolve lithologic units and associated acoustic impedance contrasts only on the order of $10 \mathrm{~m}$. Despite the different resolution capabilities of the water gun and downhole logging instruments, the deconvolved seismic data are in good agreement with the downhole acoustic impedance contrasts (Fig. $17 \mathrm{~A},-\mathrm{B})$. Therefore, deconvolving the seismic reflection data has improved the correlation with both the recovered lithology above the mid-Eocene unconformity and the downhole acoustic impedance contrasts beneath the unconformity.

\section{CONCLUSIONS}

Using our deconvolution technique, a filter can be constructed to remove the sea-surface reflected signal from the composite signal, thus isolating the water-gun primary signal. Composite signals for near-vertical incidence can be generated for different water-gun towing depths given the above primary signal. Deconvolving the seismic reflection data (e.g., RC2708 line 20) with our estimated composite signal significantly improves the stratigraphic resolution of the seismic data as evidenced by the correlation with Leg 121 drilling data. Migration prior to deconvolution also improves the quality of the seismic reflection data. However, migration is about 20 times more computer intensive than deconvolution. 


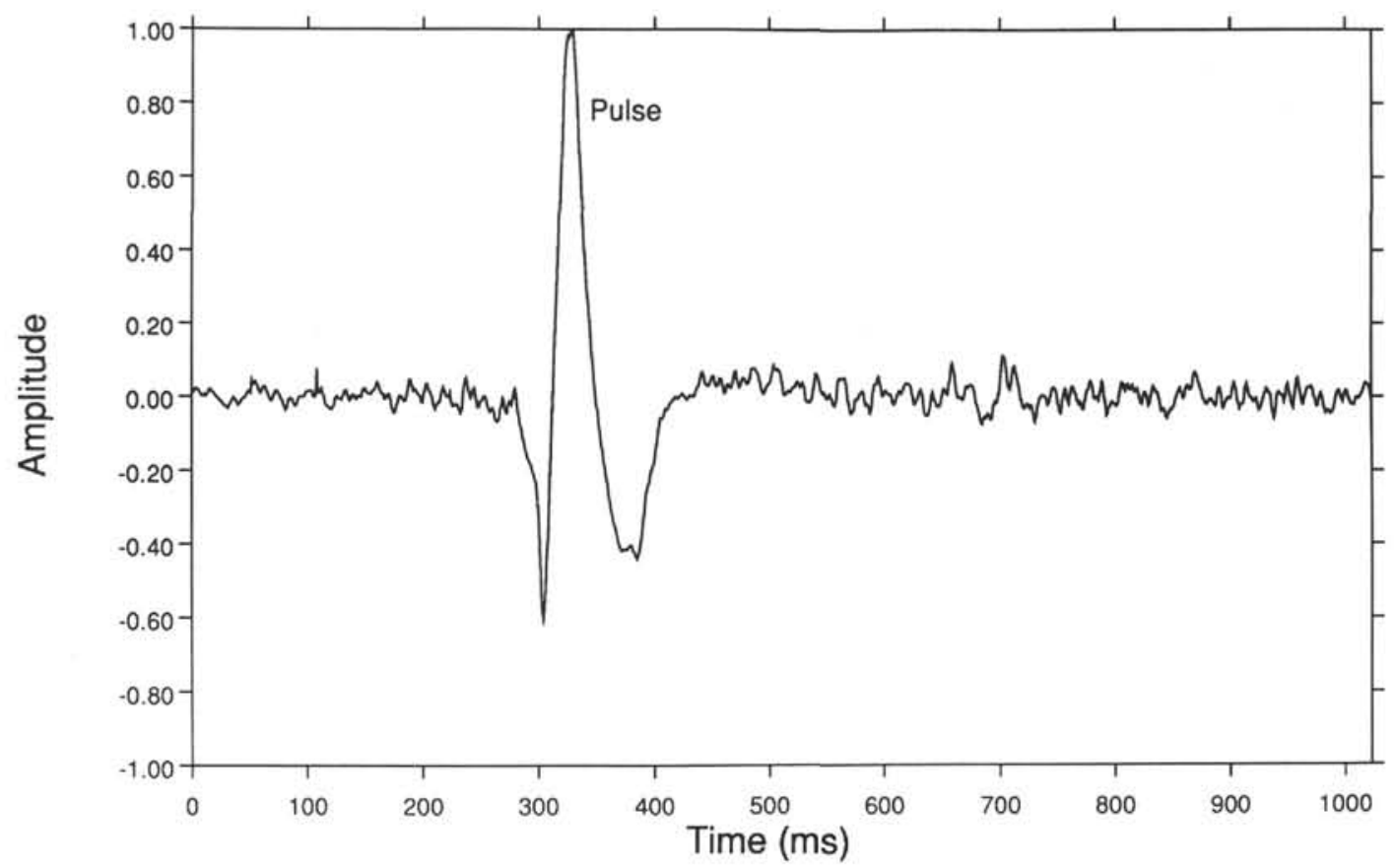

Figure 10. Stacked primary signal for shotpoints 100-105.

In addition, we show that deconvolving the seismic reflection data with the composite signal represents a best estimate of the acoustic impedance contrasts as a function of depth. This "earth filter" is in good agreement with independently derived acoustic impedance contrasts from downhole logging data at Sites 752 and 754. Therefore, we recommend that during single-channel seismic experiments, a sonobuoy receiver (SSQ-57A) be deployed to record the composite water-gun signal in order to deconvolve the seismic reflection data.

\section{ACKNOWLEDGMENTS}

We wish to thank P. Buhl, J. Diebold, R. Flood, and J. Weissel for the many discussions which made this a better manuscript. J. Diebold, G. Moore, J. Payne, C. Peach, and J. Weissel critically reviewed this manuscript and their comments are greatly appreciated. Major support for this work was from USSAC/JOI through TAMRF P.O. \#20248 and \#20258. Lamont-Doherty Geological Observatory contribution 4808 .

\section{REFERENCES}

Dragoset, W. H., 1990. Air-gun array specs: a tutorial. Geophysics: The Leading Edge of Exploration, 9:24-33.

Driscoll, N. W., Karner, G. D., Weissel, J. K., and Shipboard Scientific Party, 1989. Stratigraphic and tectonic evolution of Broken Ridge from seismic stratigraphy and Leg 121 drilling. In Peirce, J., Weissel, J., et al., Proc. ODP, Init. Repts., 121: College Station, TX (Ocean Drilling Program), 71-91.
French, W. S., and Henson, C. G., 1978. Signature measurements on the water gun marine seismic source. Offshore Technol. Conf., no. 3124.

Jovanovich, D. B., Sumner, R. D., and Akins-Easterlin, S. L., 1983. Ghosting and marine signature deconvolution: a prerequisite for detailed seismic interpretation. Geophysics, 49:1468-1485.

Jurkevics, A., and Wiggins, E., 1984. A critique of seismic deconvolution methods. Geophysics, 49:2109.

Lindsey, J. P., 1959. Elimination of seismic ghost reflections by means of a linear filter. Geophysics, 25:130-140.

Newman, B. J., 1986. Deconvolution of noisy seismic data-A method for prestack wavelet extraction. Geophysics, 51:34-44.

Peirce, J., Weissel, J., et al., 1989. Proc. ODP, Init. Repts., 121: College Station, TX (Ocean Drilling Program).

Robinson, E. A., and Treitel, S., 1980. Geophysical Signal Analysis: Englewood Cliffs, NJ (Prentice-Hall).

Safar, M. H., 1984. On the S80 and P400 water guns: a performance comparison. First Break, 2:20-24.

Schlich, R., Wise, S. W., Jr., et al., 1989. Proc. ODP, Init. Repts., 120: College Station, TX (Ocean Drilling Program).

Sheriff, R. E., 1977. Limitations on resolution of seismic reflections and geologic detail derivable from them. In Clayton C. E. (Ed.), Seismic Stratigraphy: Application to Hydrocarbon Exploration. AAPG Memoirs, 26:49-58.

1985. Aspects of seismic resolution. In Berg, O. R., and Woolverton, D. G. (Eds.), Seismic Stratigraphy II: An Integrated Approach to Hydrocarbon Exploration. AAPG Memoirs, 39:1-12.

Date of initial receipt: 6 April 1990

Date of acceptance: 10 October 1990

Ms 121B-156 
Time (ms)
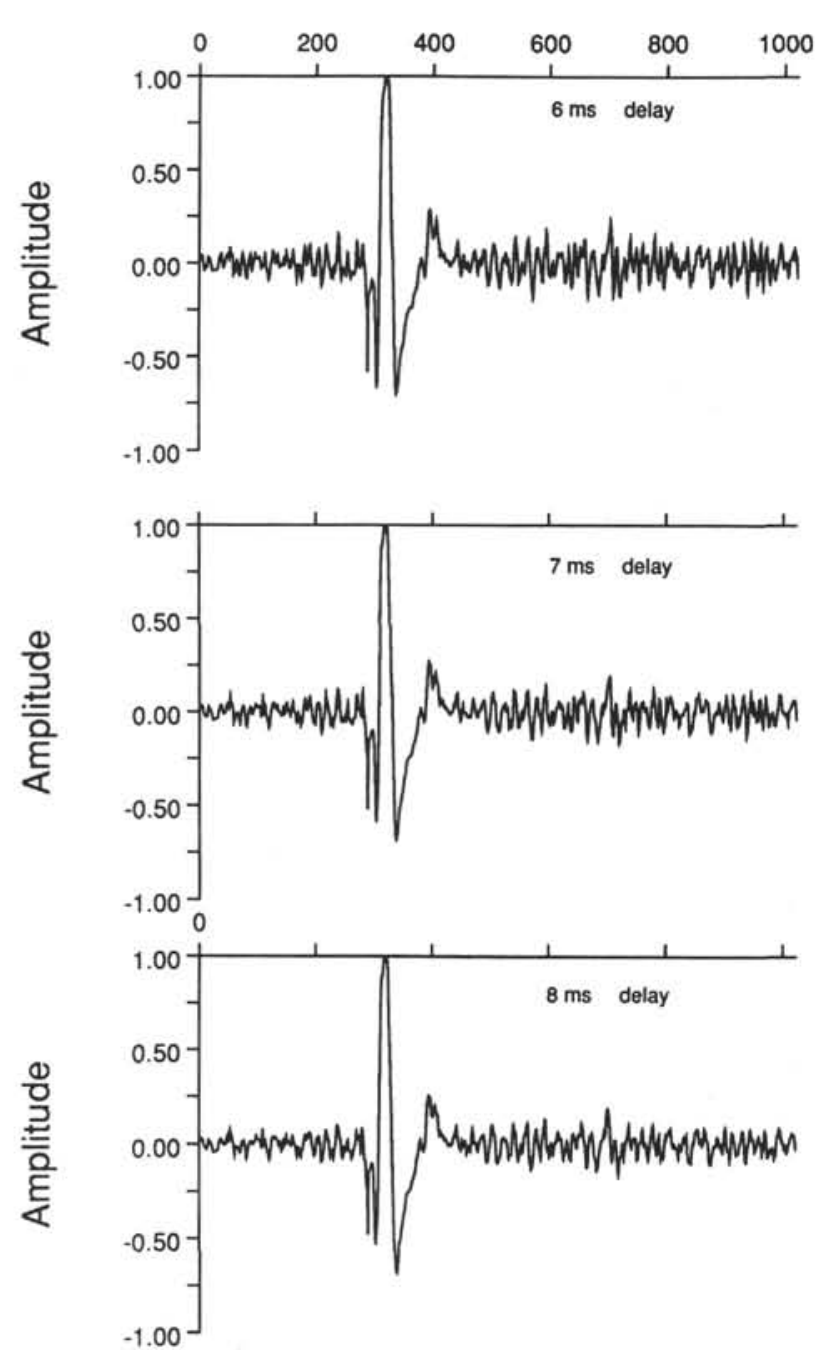

Figure 11. Synthetic composite signals at near-vertical incidence generated for different water-gun towing depths. The delay $(\Delta t)$ between the primary and sea-surface reflected signal depends on the water-gun depth (i.e., 7-ms delay $=5.25-\mathrm{m}$ gun depth). Note the towing depth of the water gun appears to have little or no effect on the composite signal in the time domain.
Frequency $(\mathrm{Hz})$
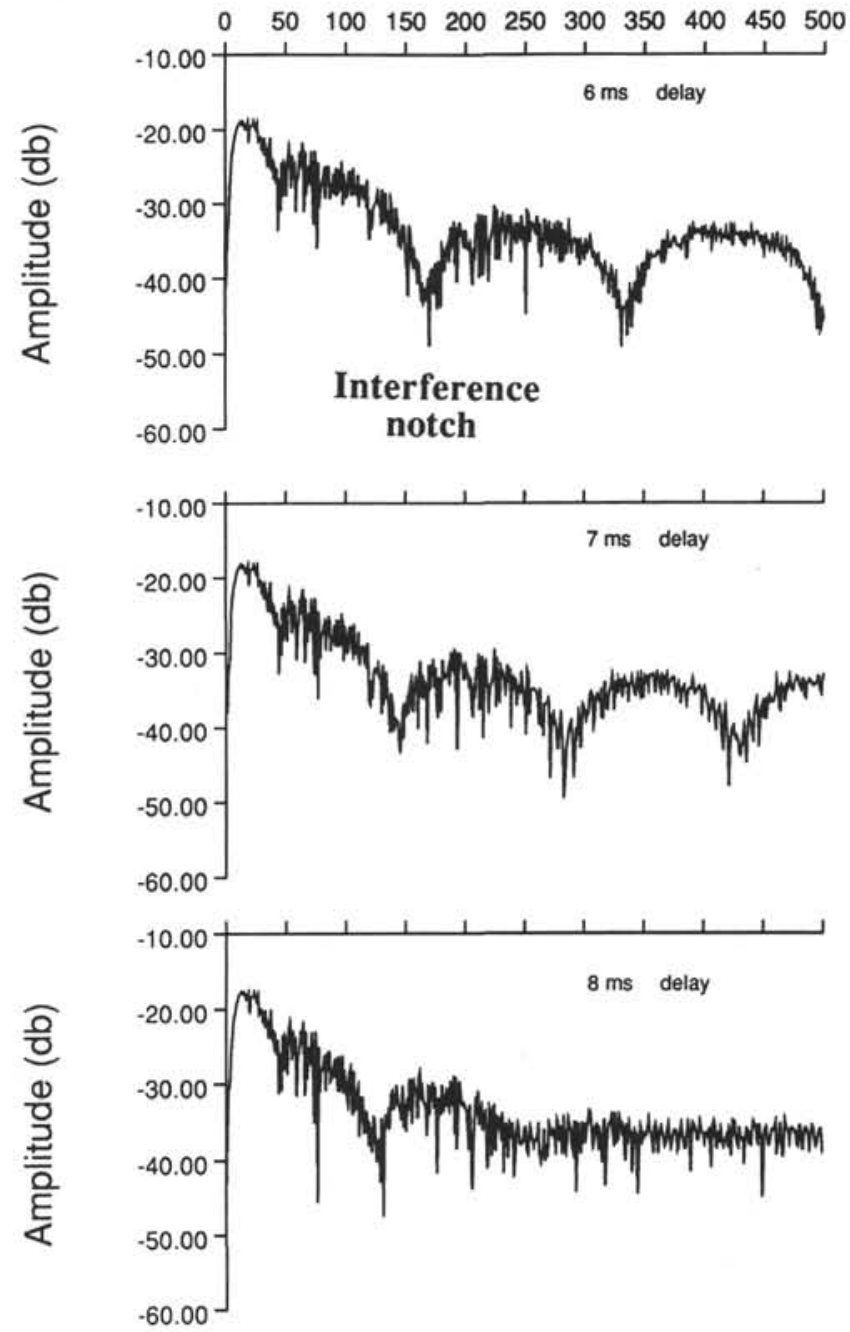

Figure 12. Amplitude spectrum of the synthetic composite signals at near-vertical incidence, but different gun depths. The composite signal is very sensitive to the delay (water-gun depth) in the frequency domain. Note that the interference notch shifts to lower frequencies with increasing gun depth. The first non-zero frequency at which the interference notch occurs is diagnostic of gun depth. 


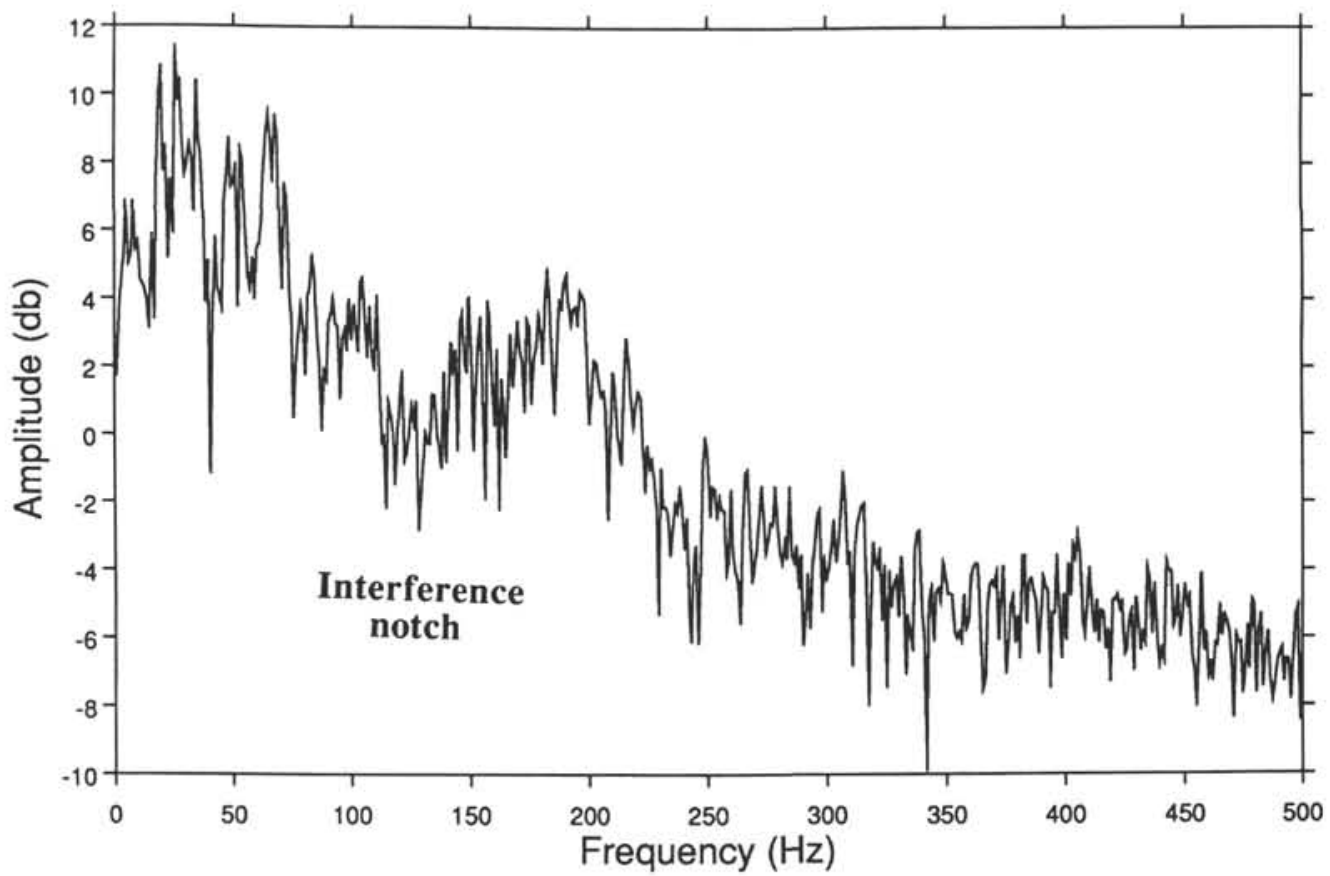

Figure 13. Amplitude spectrum of the stacked composite signals recorded by the streamer. Shotpoints $935-939$ recorded on RC2708 line 20 were summed to remove any spurious noise. The amplitude spectrum of the summed traces reveals the first non-zero frequency at which the interference notch occurs. The interference notch is centered at $130 \mathrm{~Hz}$, suggesting a water-gun depth of $5.8 \mathrm{~m}$ for line 20 . 


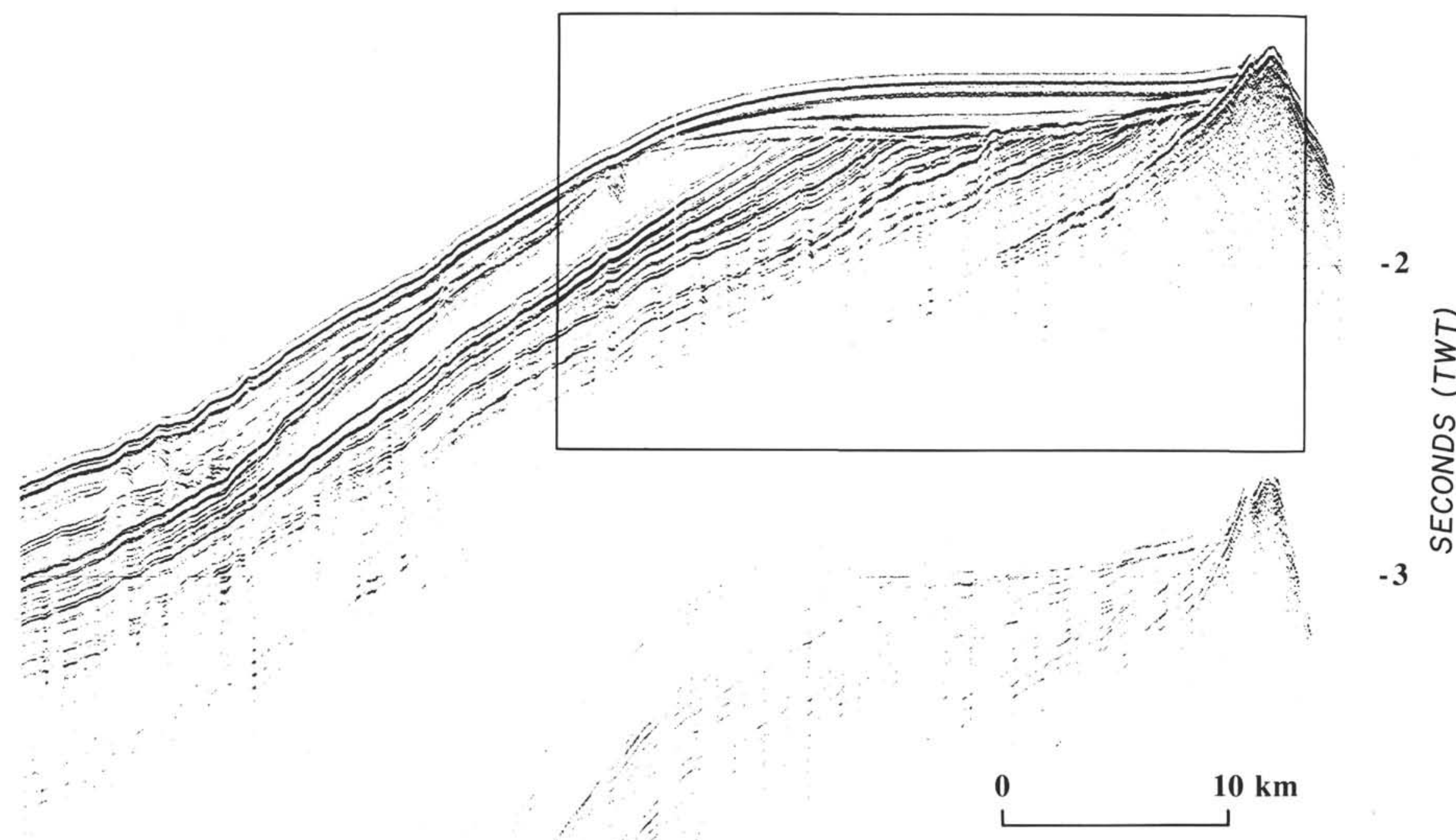


A

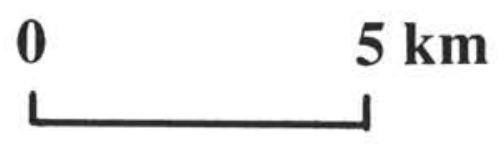




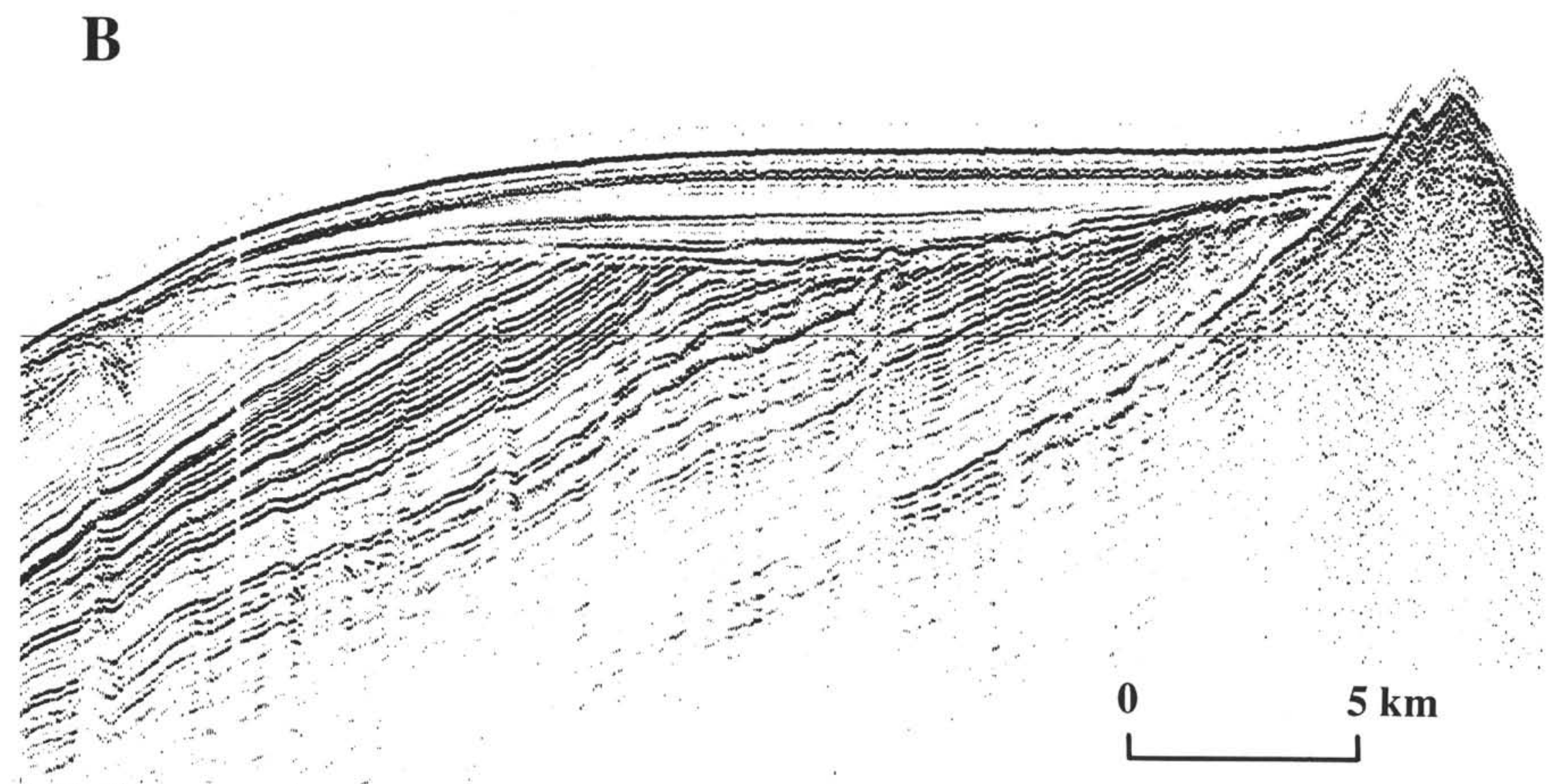

Figure 15. A. Line 20 band-pass filtered $20-140 \mathrm{~Hz}$. B. Line 20 deconvolved with composite signal $(\Delta) t=8 \mathrm{~ms})$ and then band-pass filtered $20-140 \mathrm{~Hz}$. C. Line 20 migrated and corrected for spherical divergence with velocity data, and then band-pass filtered $20-140 \mathrm{~Hz}$. D. Line 20 migrated and corrected for spherical divergence, deconvolved with composite signal $(\Delta \mathrm{t}=8 \mathrm{~ms})$, and then band-pass filtered $20-140 \mathrm{~Hz}$. 
C

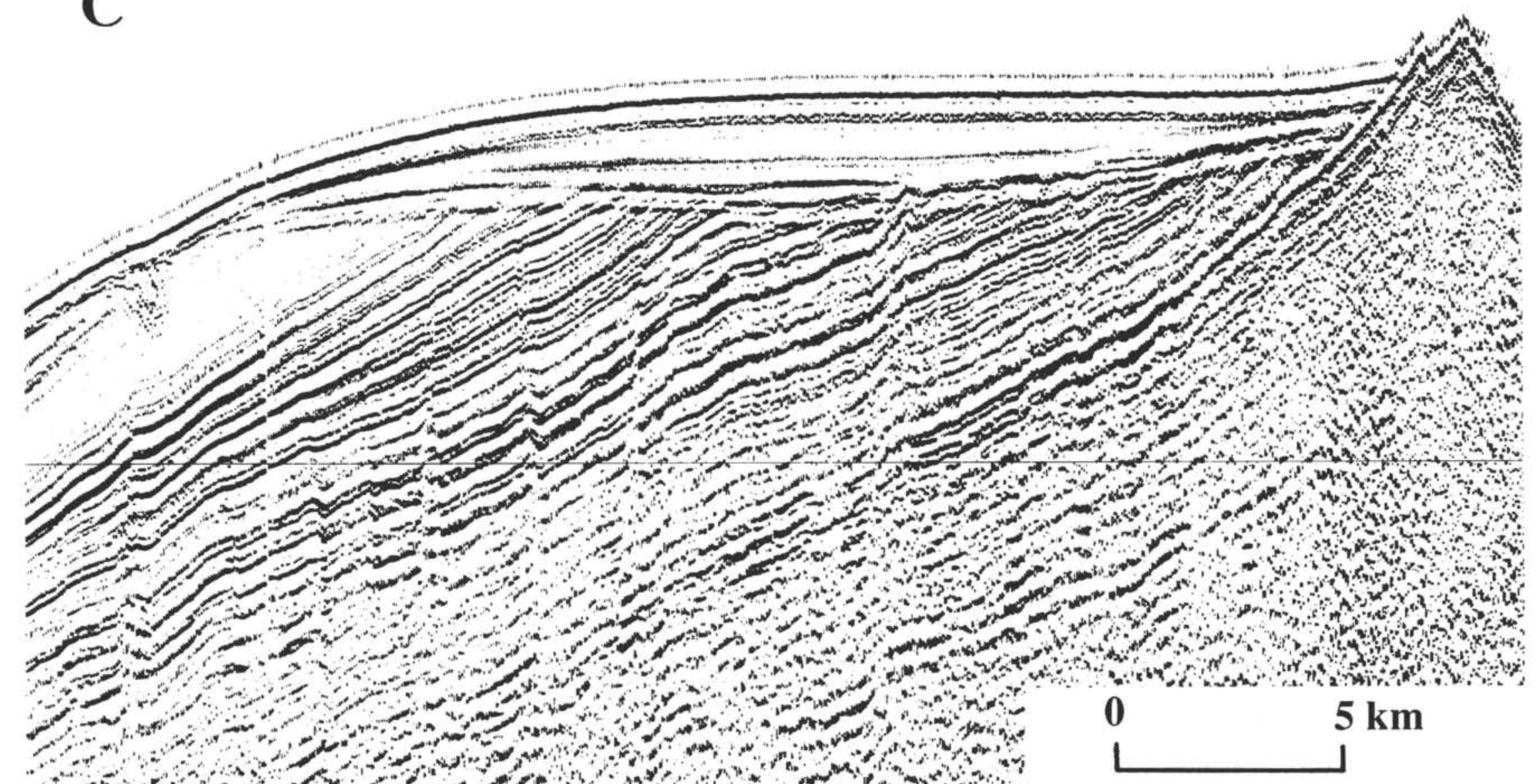




\section{D}

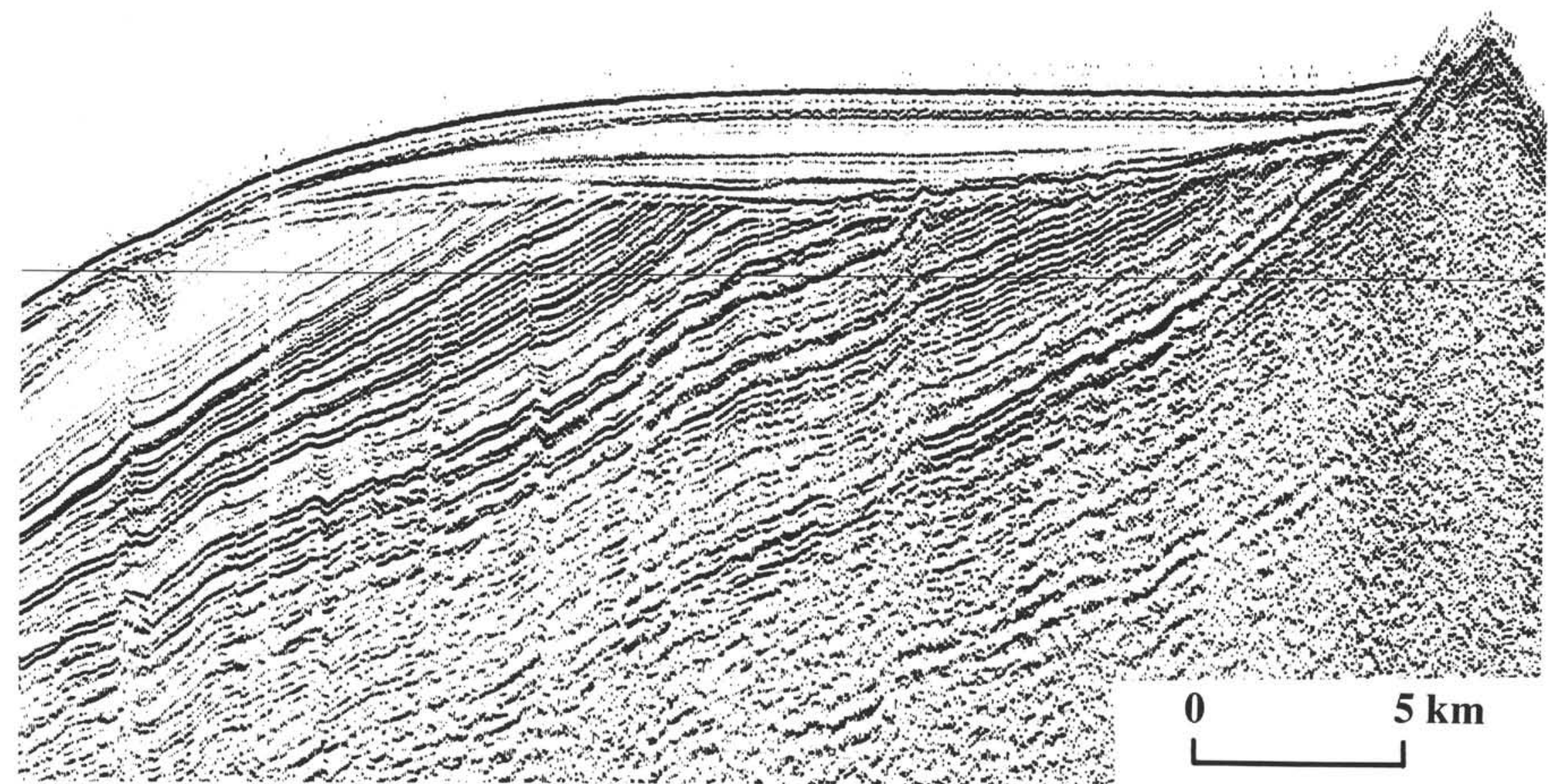

Figure 15 (continued). 


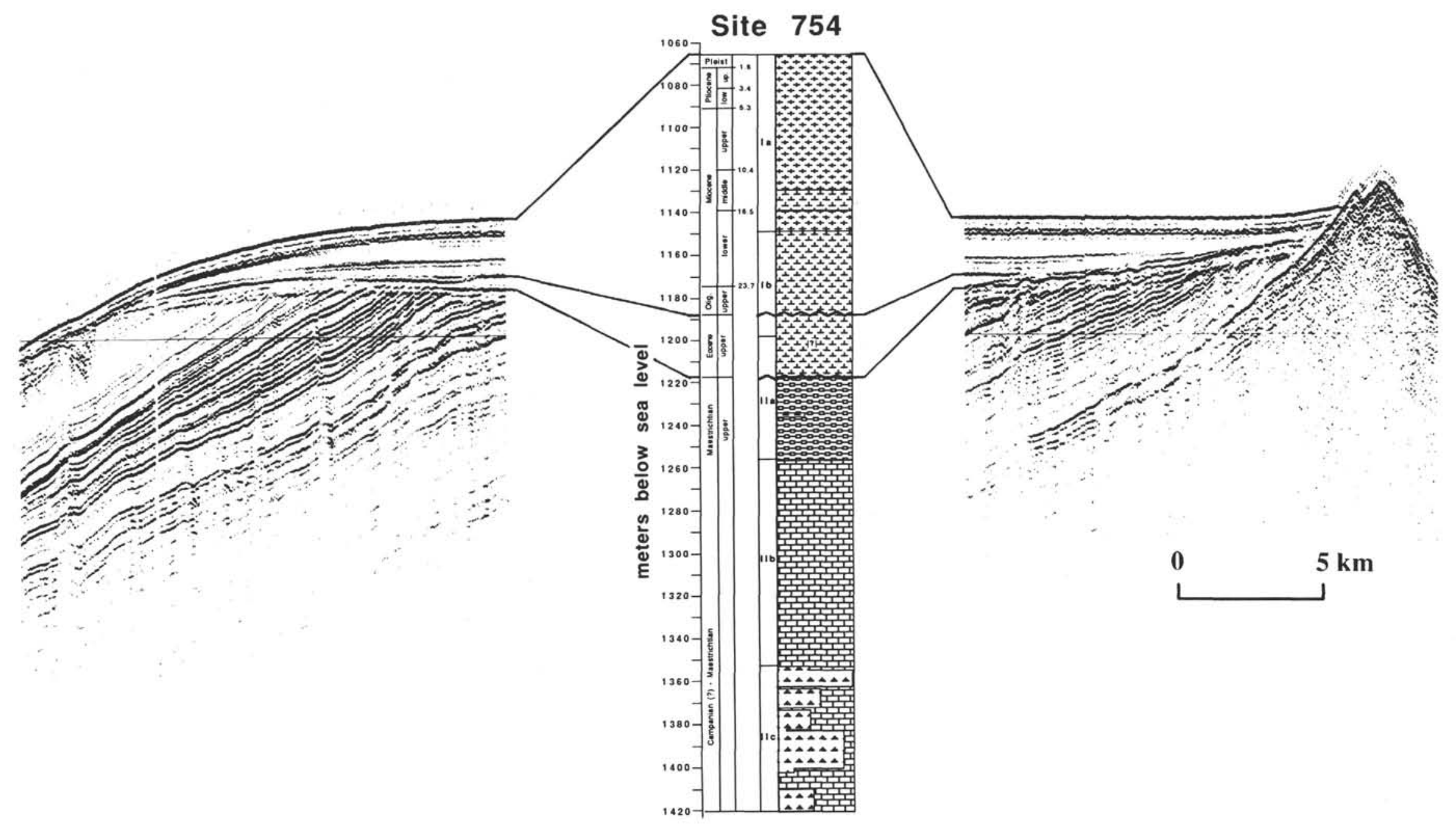

Figure 16. Correlation of deconvolved seismic reflection data with Site 754. Deconvolving the data removed the water-gun precursor and better resolved the unconformities identified at Site 754. Note the deconvolved data imaged the gravel unit bounded by the Oligocene and mid-Eocene unconformities. 
A

RC2708 Line 20
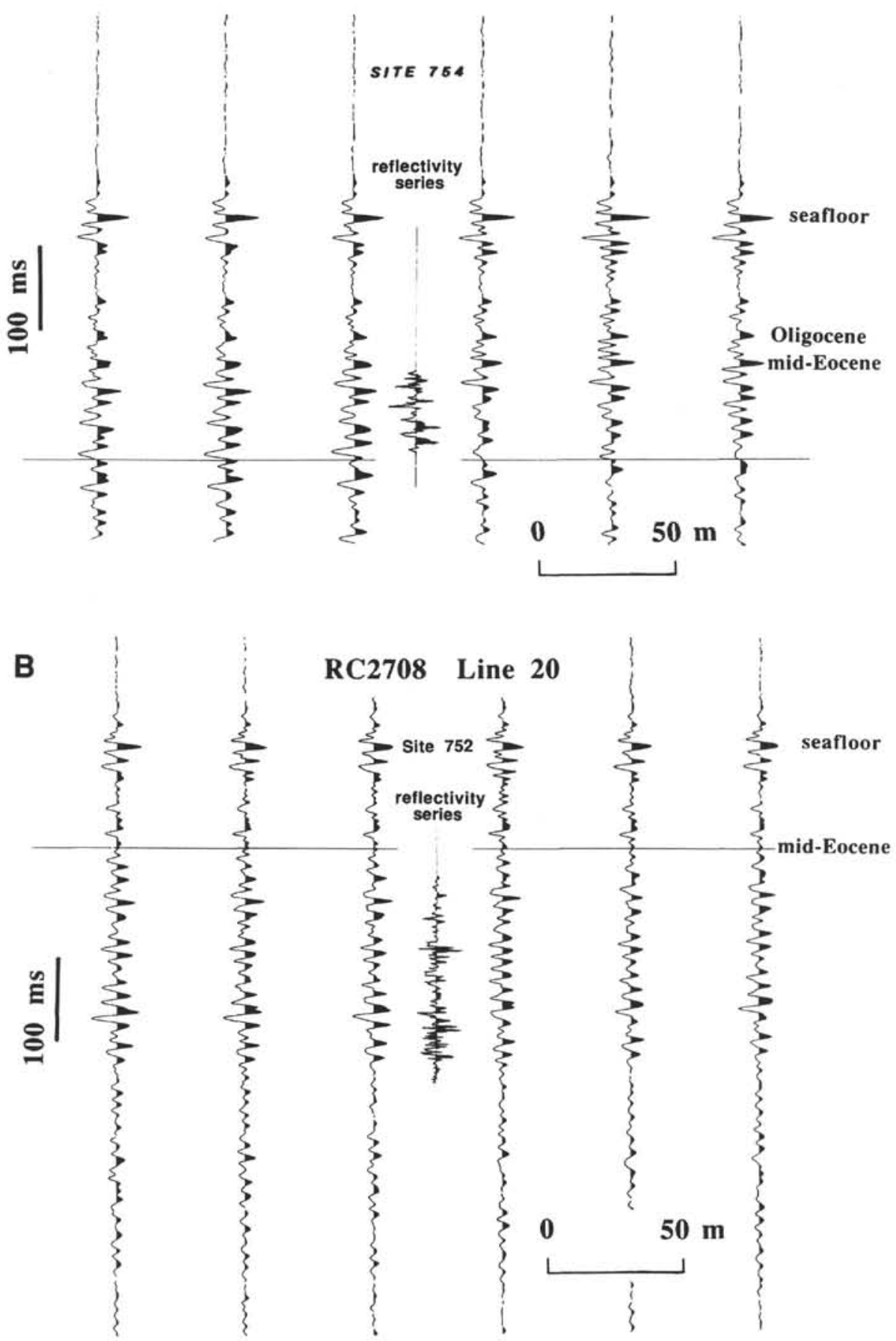

Figure 17. A. Correlation of deconvolved seismic reflection data shown in Figure 15B with the downhole acoustic impedance contrasts at Site 754. B. Correlation of deconvolved seismic reflection data shown in Figure 15B with the downhole acoustic impedance contrasts at Site 752. The downhole acoustic impedance contrasts (i.e., reflectivity series) were generated from the velocity and density data sampled at $0.153-\mathrm{m}$ intervals at Sites 752 and 754. Note the agreement between the deconvolved data and the downhole acoustic impedance contrasts. The seafloor, Oligocene unconformity, and mid-Eocene unconformity are labeled for clarity. 